\section{Preventive behaviours in avoiding indoor secondhand smoke exposure among pregnant women in China}

\section{DEAR EDITOR}

Secondhand smoke (SHS) is a major indoor pollutant that causes serious health problems among all those exposed, especially pregnant women. ${ }^{1}$ Prevalence of exposure to SHS among pregnant women is high in China. ${ }^{2}$ In the 2010 Global Adult Tobacco Survey in China, $65.1 \%$ of non-smoking women of childbearing age were exposed to SHS at home and another $52.6 \%$ were exposed to SHS in the workplace. ${ }^{3}$ Globally, it was estimated that about one-third of adults $33 \%$ men and $35 \%$ women) are exposed to SHS, ${ }^{4}$ which is comparatively lower than the exposure level in Chinese women. This pattern of exposure to SHS among adults highlights the fact that many of the over 100 million annual pregnant women globally will be exposed to SHS, and will expose their unborn children to tobaccoinduced harms. ${ }^{1}$ Therefore, public health implications of exposure to SHS during pregnancy by women and their babies are substantial $^{3}$ and need urgent attention. This study examined the behavioural practices of pregnant Chinese women in avoiding exposure to SHS in indoor environments.

A cross-sectional survey, using a structured questionnaire, was conducted among pregnant women, recruited from 16 hospitals in 5 provinces of China, from June to August 2015. The study protocol was approved by the Ethics Committee of Chongqing Medical University. All the participants in the study gave written informed consent. The participants were asked about the preventive measures they had taken to avoid exposure to SHS in indoor environments based on five response categories: (1) Open a window to improve ventilation, (2) Walk away, (3) Dissuade, (4) Ignore and (5) Not applicable. We also examined how the respondents' preventive behaviours changed due to the relationship with the smoker. Relationships examined were: Stranger, Colleague, Friend, Relative, Father-in-law, Mother-in-law, Father, Mother and Husband.

Of the total number of participants $(\mathrm{N}=2345), 74.84 \%$ were pregnant for the first time, and for the remaining $25.16 \%$ this was their second pregnancy; the mean age of the participants was 28.12 years
(SD 4.13 years), 80.17\% were from urban areas, and $3.84 \%$ were smokers. The participants were educated up to junior middle school or below, high school or vocational/technical secondary school and junior college, and senior college and university or above and their percentages were $17.14 \%, \quad 15.10 \%$ and $67.76 \%$, respectively. Table 1 shows that the preventive measures taken varied among the participants according to the nature of relationship with the smokers. Some pregnant women walked away more often when a stranger $(72.92 \%)$ or a friend $(36.42 \%)$ was a smoker, and less often when the mother $(17.06 \%)$ or the husband (19.66\%) was a smoker. Some participants choose to open a window more often when a friend $(15.91 \%)$ or a colleague $(12.75 \%)$ was a smoker, and less often in case the mother-in-law $(5.20 \%)$, or the mother $(4.56 \%)$ was a smoker; some participants choose to ignore more often in case of strangers $(4.48 \%)$ or a colleague $(2.60 \%)$ was a smoker, and less often in case the mother $(1.83 \%)$ or the husband $(1.75 \%)$ was a smoker; others choose to dissuade more often a colleague $(37.10 \%)$ or the husband (34.41\%), and less often the mother-in-law $(17.48 \%)$ or the mother (18.85\%).

The findings of this study have implications on the WHO recommendations on prevention and management of tobacco use and SHS exposure during pregnancy, especially on the protection of fetus from exposure to SHS during pregnancy. ${ }^{1}$ Usually, in the face of exposure to SHS in indoor environment, the more close the relationship of the respondent with the smoker, the more the possibility of dissuading smoking. Among family members, the smallest percentage of pregnant women dissuaded their mother-in-law from smoking indoors to prevent exposure to SHS. This is due to the sensitive nature of relationship between a mother-in-law and a daughterin-law in China. It is likely that pregnant women were concerned about disrupting family harmony if they asked their husbands or other family members to stop smoking, ${ }^{5}$ because smoking is socially acceptable in China. The preventive measures that we have identified are the common measures practiced by pregnant Chinese women to avoid exposure to SHS. These measures may be not particularly effective at protecting pregnant women as they do not strictly follow the complete ban on exposure to SHS at home or elsewhere. Also, China's indoor smoking policies differ by region and are mostly implemented in major cities. ${ }^{6}$ Moreover, the policies do not include smoking in workplaces. ${ }^{6}$ Although active smoking among Chinese women is low, because of the high rates of male smoking and the lack of enforcement of smoking laws in workplaces or public places the exposure to SHS is relatively high among women in China. The findings of this study highlight the difficulties of pregnant Chinese women in avoiding complete exposure to SHS and point to the urgent need to promote a complete ban on home smoking and restrictions on smoking in public places and workplaces in China. The findings have implications for other countries with similar sociocultural norms, especially countries in Asia and the Middle East, to adopt article 8 of the WHO Framework Convention on Tobacco Control that requires parties to implement and enforce smoke-free policies to protect people from exposure to tobacco smoke. ${ }^{7}$
Table 1 Measures taken by pregnant women to avoid indoor secondhand smoke exposure by relationships with the smoker $(n, \%)$

\begin{tabular}{lllllr}
\hline \multicolumn{5}{c}{ Measures taken by pregnant women } \\
\cline { 2 - 6 } Smoker & $\begin{array}{l}\text { Open a window to } \\
\text { improve ventilation }\end{array}$ & Walk away & Dissuade & \multicolumn{1}{l}{ Ignore } & Not applicable \\
\hline Stranger & $202(8.61)$ & $1710(72.92)$ & $111(4.73)$ & $105(4.48)$ & $217(9.25)$ \\
Colleague & $373(15.91)$ & $854(36.42)$ & $569(24.26)$ & $59(2.52)$ & $490(20.90)$ \\
Friend & $299(12.75)$ & $655(27.93)$ & $870(37.10)$ & $61(2.60)$ & $460(19.62)$ \\
Relative & $262(11.17)$ & $718(30.62)$ & $551(23.50)$ & $55(2.35)$ & $759(32.37)$ \\
Father-in-law & $196(8.36)$ & $617(26.31)$ & $577(24.61)$ & $60(2.56)$ & $895(38.17)$ \\
Mother-in-law & $122(5.20)$ & $432(18.42)$ & $410(17.48)$ & $47(2.00)$ & $1334(56.89)$ \\
Father & $173(7.38)$ & $504(21.49)$ & $662(28.23)$ & $43(1.83)$ & $963(41.07)$ \\
Mother & $107(4.56)$ & $400(17.06)$ & $442(18.85)$ & $43(1.83)$ & $1353(57.70)$ \\
Husband & $155(6.61)$ & $461(19.66)$ & $807(34.41)$ & $41(1.75)$ & $881(37.57)$ \\
\hline
\end{tabular}




\section{Xianglong $\mathrm{Xu}_{1}{ }^{1,2,3}$ Yunshuang Rao, ${ }^{4}$ Abu S Abdullah, ${ }^{5,6}$ Manoj Sharma, ${ }^{7}$ Jeff J Guo, ${ }^{8}$ Yong Zhao ${ }^{1,2,3}$}

${ }^{1}$ School of Public Health and Management, Chongging Medical University, Chongqing, China

${ }^{2}$ Research Center for Medicine and Social Development, Chongqing Medical University, Chongqing, China

${ }^{3}$ The Innovation Center for Social Risk Governance in Health, Chongqing Medical University, Chongqing, China

${ }^{4}$ School of Nursing, Chongqing Medical University, Chongqing, China

${ }^{5}$ Global Health Program, Duke Kunshan University, Kunshan, Jiangsu Province, China

${ }^{6}$ Duke Global Health Institute, Duke University, Durham, USA

${ }^{7}$ Behavioral \& Environmental Health, Jackson State University, Jackson, Mississippi, USA

${ }^{8}$ College of Pharmacy, University of Cincinnati Medical Center, Cincinnati, Ohio, USA

Correspondence to Professor Yong Zhao, School of Public Health and Management, Chongqing Medical University. No, 1 Yixueyuan Road, Yuzhong District, Chongqing 400016, China; zhaoyong@cqmu.edu.cn

Acknowledgements The authors would like to thank all those who participated in this study. This project was supported by the Medjaden Academy \& Research Foundation for Young Scientists (Grant number MJR20150047) and China Ministry of Education of Humanities and Social Science Research (number 15YJA860020).

Contributors XX was responsible for analysis, literature searches, interpretation of the results and writing the manuscript. YR, ASA, MS, JJG and YZ contributed to the drafting of the manuscript. All authors contributed to the concept of the article, reviewed the final version of the paper and approved it for publication.

Funding The Medjaden Academy \& Research Foundation for Young Scientists. Grant number MJR20150047.

Competing interests None declared.

Patient consent Obtained.

Ethics approval The Ethics Committee of Chongqing Medical University.

Provenance and peer review Not commissioned; externally peer reviewed.

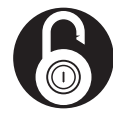

\section{OPEN ACCESS}

Open Access This is an Open Access article distributed in accordance with the Creative Commons Attribution Non Commercial (CC BY-NC 4.0) license, which permits others to distribute, remix, adapt, build upon this work non-commercially, and license their derivative works on different terms, provided the original work is properly cited and the use is noncommercial. See: http://creativecommons.org/licenses/ by-nc/4.0/

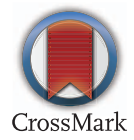

To cite Xu X, Rao Y, Abdullah A S, et al. Tob Control 2017;26:483-484.
Received 14 March 2016

Revised 3 June 2016

Accepted 27 June 2016

Published Online First 18 July 2016

Tob Control 2017; 26:483-484.

doi:10.1136/tobaccocontrol-2016-053047

\section{REFERENCES}

1 World Health Organization. WHO recommendations on prevention and management of tobacco use and secondhand smoke exposure in pregnancy. Geneva: WHO, 2014. http://www.who.int/tobacco/publications/ pregnancy/en/ (accessed 1 Jun 2016).

2 Zhang L, Hsia J, Tu X, et al. Exposure to secondhand tobacco smoke and interventions among pregnant women in China: a systematic review. Prev Chronic Dis 2015;12:E35.

3 Centers for Disease Control and Prevention. Current tobacco use and secondhand smoke exposure among women of reproductive age - 14 countries, 20082010. MMWR Morb Mortal Wkly Rep 2012:61:877-82

4 World Health Organization. Global estimate of the burden of disease from secondhand smoke. Geneva, Switzerland, 2011. http://apps.who.int/iris/ bitstream/10665/44426/1/9789241564076_eng. pdf

5 Lee $\mathrm{AH}$. A pilot intervention for pregnant women in Sichuan, China, on passive smoking. Patient Educ Couns 2008;71:396-401.

6 Parry J. China pushes ahead with ban on indoor smoking. BMJ 2011;342:d1990

7 World Health Organization Guidelines for Implementation of Article 8. http://www.who.int/fctc/ guidelines/adopted/article_8/en/ (accessed 20 Apr 2014). 